\title{
Classroom Sense of Community and Academic Achievement: Mediating role of Academic Hardiness and Moderating Role of Gender
}

\author{
Kanwal Gul ${ }^{1}$, Dr Irfan Hyder ${ }^{2}$ \\ Institute of Business Management, Pakistan
}

\begin{abstract}
The rationale of the study was to investigate the role of (a) academic hardiness (control, commitment and challenge) as a mediator between classroom sense of community and academic achievement and (b) gender as a moderator between classroom sense of community and academic achievement. 159 students from 18-24year old took part in the study by completing a validated questionnaire. Partial Linear Square procedure was used and presented evidence that academic hardiness as a whole (control, commitment and challenge) do not mediate relationship between classroom sense of community and academic achievement and but Challenge moderates the relationship between Classroom sense of community and academic hardiness. Gender also does not mediate relationship between classroom sense of community and academic achievement among Pakistani university students. These results contribute in the existing literature and also provides an insight of the behaviour and perceptions of Pakistani students to achieve grades and willingness of accord him or herself with the class room or university environment by expressing academic hardiness mediation role and gender as a moderation role between classroom sense of community and academic achievement.
\end{abstract}

Keywords: Classroom Sense of Community, Academic Hardiness, Academic Achievement. 


\section{Introduction}

It is a known fact that a country`s development depends upon students`academic achievement and development, that is the reason that every country emphasises on advancing students`AcaAch (Rana \& Mahmood, 2010). Developing countries i.e. Pakistan witnesses an overwhelming task to improve educational services due to increasing population and their tight budgetary constraints (Alderman, Orazem, \& Paterno, 2001). Whereas, Low AcaAch has universal significance, exercising adverse influence on student, familial and societal effects (Chen, 2015). However, very few studies have been carried out on AcaAch among Pakistani students. Classroom sense of community, AcaHar are two variables found to influence AcaAch, but have not been found a thorough study among Pakistani university students. Therefore, the purpose of this study to contribute in the existing literature by investigating (a) direct relationship of classroom sense of community and AcaAch, (b) AcaHar as a mediator between CSC and AcaAch and (c) gender as a moderator between CSC and AcaAch.

Many researchers worked on Hardiness and termed is as a Personality Characteristic (Beasley, Thompson, \& Davidson, 2003). Hardiness theory was first explained by Kobasa, defined as the individual personality style treated as under good health or under stress. He developed a framework which gave an understanding of why certain students keen to accept more challenging coursework (Kobasa, 1979). In 1982, Kobasa explained three personality dispositions attached with cognitive processes that are aligned with different life circumstances (Kobasa, Maddi, \& Kahn, 1982). A multi-dimensional concept of Academic Hardiness was first proposed by (Benishek, Feldman, Shipon, Mecham, \& Lopez, 2005) which was originally originated from combination of Hardiness Theory and Dweck`s (2000) Theory of Academic Motivation. In real, AcaHar is an ability to apply three components-Commitment, Control and Challenge- to achieve academic excellence (Benishek, Feldman, Shipon, Mecham, \& Lopez, 2005).

Commitment is a propensity to connect oneself in any work. A Committed person has purposeful events that allow him to find the best alternative in terms of events, things and individuals as well. Committed individuals are so mature that they don't give up even in 
pressurized situations. Overall, a committed individual has an ability to involve actively rather than passively and face avoidance (Kobasa, Maddi, \& Kahn, 1982).

Control is defined as the tendency to influence one to act and feel in a diverse incidents of life (Selingman, 1992). Control help in enhancing stress confrontation by boosting likelihood chances of events that will be result of natural consequence of one`s actions and is not affected by any other outer experience. A sense of Control leads to a consistent experiences in a controlled environment and leads to low jarring (Kobasa, Maddi, \& Kahn, 1982).

Challenge is uttered as a belief that changes rather than stability is normal in life and these changes provide ample opportunities for growth rather than threats (Csikszentmihalyi, 1975). Challenge depicts colour events to stimulate rather to threat, the reason is challenge creates chances to readjust the situation. By applying openness and flexibility, challenge should accept the incorporation and effective management of even distinct situations (Moss, 1973).

Students`AcaHar quality is influenced by a vast variety of environmental factors. AcaHar is much important especially for students, educationists, educational institutions and curriculum practises as well. (Kobasa, Maddi, \& Kahn, 1982). The three integrated hardiness attitudes; Commitment; Control and Challenge enhances individual performance (Kobasa S. C., 1979).

The third important centre for change in higher education is the continuous growing attention being given to Classroom Sense of Community, A educational place is a learning environment where students learn teamwork coordination, work in cultural and personality diversity and every student care about their trust and respect each other; all community members work for the shared vision for their future with a single purpose alongwith a common set of values for all (Rovai, Wighting, \& Lucking, 2004). McMillan \& Chavis(1986) gave the following definition for Classroom Sense of Community "a feeling that members have of belonging, a feeling that members matter to one another and to the group, and a shared faith that members' needs will be met through their commitment to be together". A strain had been developed by researchers for valuable community in schools in terms of binding of learners and teachers by sharing their values, goals and ideas (Sergiovanni \& J., 1994). 
Classroom Sense of Community theorized with its four components that are spirit, interaction, trust, and learning (Rovai, 2001). All components include four dimensions of McMillan`s (1996) community as applied in a classroom setting. Spirit is the aspiration of acceptance and belongingness to a community with feeling of friendship, unity and satisfaction that widens among members of the community. In combination with the sense of community concept is McMillan`s dimension of spirit, trade and art. Reason to combine these dimension was during a pilot study conducted by Rovai and Luking; using the exploratory factor analysis (EFA) to develop a measure for classroom community was failed to dig out spirit trade and art as separate factors, which suggested them as the part of the same construct.

Trust is the feeling that community and its members can be trusted and continuous improvement through feedback will be productive and forthcoming. As members selected for a specific community, a sense of safety and trust develops among them, which help members to express their feelings openly. This trust factor is much important for a learning community, as it make members to express the gaps in the community by feeling safe and secure that will lead to community improvement "When there is trust among people, relationships flourish; without it, they wither" (Preece, 2000).

Interaction is the sentiment that mutual and closeness with community members comes with interaction with others. Interaction is either task-driven or socio-emotional in origin (Blumberg, Kent, Haire, \& Davies, 1994). According to Cutler "the more one discloses personal information, the more others will reciprocate, and the more individuals know about each other, the more likely they are to establish trust, seek support, and thus find satisfaction" (Cutler \& R.H, 1996). Vrasidas \& Mclsaac(2009) remarked that structuring of dialogues is very important for educators due to the learner-learner interaction treated as the dialogue component. Hence, Interaction should be treated as important factor for learning and community development.

Learning is the sense of feeling that knowledge and meaning are integral part of community, which satisfies members to learn and understand knowledge. For the community development, members not only participate in the community but also accepts groups`values and purpose at least partially (Rovai, 2001) . It is witnessed that learning is the part of sense of community, i.e. Bryk \& Driscoll(1998) conducted a research on high school population and concluded that 
sense of community is narated to create interest in academics and future educational acheivements.

In the global and technological era, education is treated as the first step towards human development. It play a key role in the human development and creates ample growth opportunities (Battle \& Lewis, 2002). Education is treated as the top most priority for human development regionally, nationally and globally that effects students`AcaAch (Crosnoe, Johnson, \& Jr., 2004). AcaAch is such a unstructured term which make it difficult to explain in a structured way. However, it is sure that it includes many different skills and abilities (Bentley, 1966). AcaAch and Gender relationship discussed for decades (Eitle, 2005). A gender gap have been found between boys and girls that girls are better academic performers than boys (McCoy, 2005)

\section{Purpose of the Study}

The study aims to provide an understanding of mechanism essential for the relationship of classroom CSC leading to AcaAch. Three Dimensional AcaHar concept have been tested as a mediator between classroom sense of community and AcaAch to examine how classroom sense of community via mediating role of AcaHar (control, commitment and challenge) leads to AcaAch in the university students of Pakistan. This mediating role of AcaHar provides a firm basis for the assumption that students with high classroom sense of community are more prone to presume an AcaHar attitude that can help out in accomplishment of AcaAch. Students equipped with greater AcaHar are less likely to shun academic tasks, because they are not threaten with AcaHar and do not treat as a hurdle in their AcaAch (Ahmadi, Zainalipour, \& Rahmani, 2013). Role of gender as a moderator has also been tested to investigate whether is there any difference in AcaAch genders with the impact of CSC. This study was intending to measure the role of AcaHar as a mediator and role of gender as a moderator between CSC and AcaAch in university students of Pakistan.

\section{Research Hypotheses}

Based on the fore said research-driver relationship between classroom sense of community, AcaHar, gender and AcaAch; following hypotheses have been proposed: 
Hypothesis 1: AcaHar (Control) Mediates relationship between CSC and AcaAch.

Hypothesis 2: AcaHar (Commitment) Mediates relationship between CSC and AcaAch.

Hypothesis 3: AcaHar (Challenge) Mediates relationship between CSC and AcaAch.

Hypothesis 2: Gender Moderates a relationship between Classroom Sense of CSC and AcaAch

\section{Methodology}

\section{Participants}

The data for the research was collected through a designed questionnaire, based on selected scales. The respondents were university students of Pakistan. A Higher Education Commission recognized universities have been selected, which is based in Karachi city. The reason to choose this university student were because it is HEC recognized and in the top ten business schools of Pakistan and also convenience of the researchers was also kept in mind. A sample of 159 students have been selected and asked to complete the questionnaire. Different procedures were available to measure the sample size for Smart PLS path analysis (Comrey \& Lee, 1992). According to Lohmoller 1989, PLS is used because it not senstive to the size of the sample.

Table.1 Characteristics of respondents

\begin{tabular}{lrrr}
\hline Cherecristics & Frequency & Prencetange & \multicolumn{2}{c}{$\begin{array}{c}\text { Cumulative } \\
\text { Precentage }\end{array}$} \\
\hline Gender & & 59.5 & 59.5 \\
& 94 & 40.5 & 100.0 \\
Total & 64 & 100.0 & \\
Age & 158 & .6 & 77.2 \\
& 122 & 5.1 & 98.7 \\
& 34 & 93.0 & 99.4 \\
Total & 1 & 1.3 & 100.0 \\
Education & 1 & 100.0 & .6 \\
& 158 & .6 & 5.7 \\
& 1 & 5.1 & 98.7 \\
\hline Total & 8 & 93.3 & \\
\hline
\end{tabular}


Participant students were accessed through personal visits in their lecture class with prior permission of their class teachers. From Institute of Business Management, out of students in total, were 64 female respondents and 94 were male. Respondents age ranged from 18 to 22 . Out of data collected from students, $0.6 \%(n=1)$ were intermediate, $5.7 \%(n=8)$ were undergrads, 93\% $(\mathrm{n}=148)$ grade students.

\section{Procedure}

Higher Education Commission recognized university based in Karachi city was selected. Students of Business studies were selected and were asked to fill the questionnaire during their regular classes with the prior approval of class tutor. Also, in questionnaire, students were asked to write their university`s registration ID No. so that their CGPA for the period of 201819 can been accessed.

Approval from Deans of (IoBM) were received to access their students`cumulative grading point averages. Data collection took almost 4 hours a day, along with six working days, ranging from Monday to Saturday. At Institute of Business Management, no classes were held on Friday, so data collection were not done on Friday at IoBM. 200 questionnaires were floated to students during their class and received back with response rate of $79 \%$.

\section{Measures}

The research was based on the survey of 600 university students of two Higher Education Commission Pakistan`s recognized universities that is Institute of Business Management University. The survey was designed on the basis of three already validated instruments that were Classroom Sense of Community (Rovai, 2002), AcaHar (Kamtsios \& Karagiannopoulou, 2012). For AcaAch, as universities was using different cumulative grading point averages; there selective GPA system have been used for AcaAch assessment. 


\section{Academic Achievement}

AcaAch was gauged by using Cumulative Grade Point Average from respondents` transcripts for the year 2017-18. As the sample have been selected from two universities, and cumulative grade point was not standard in Pakistan. So, with the approval of universities, their cumulative grade point averages have been used as a measure of AcaAch. Both universities have two semesters in a year, fall and spring. The Cumulative Grade Point scale for Institute of Business Management follows: $\mathrm{A}+=96-100, \mathrm{~A}=91-95, \mathrm{~A}-=87-90, \mathrm{~B}+=84-86, \mathrm{~B}=79-83, \mathrm{~B}-=74-78$, $\mathrm{C}+=68-73, \mathrm{C}=65-67, \mathrm{C}-=62-64, \mathrm{D}=60-61, \mathrm{~F}<60$. To accurately measure the impact of Classroom sense of community which is based on 5 point likert scale, AcaAch also measured on 5-point scale 5=87-100, 4=79-86, 3=65-78, 2=64-61 $0=1=61$

\section{Classroom Sense of Community}

Community described as " feeling that members have of belonging, a feeling that members matter to one another and to the group, and a shared faith that members' needs will be met through their commitment to be together" (McMillan \& Chavis, 1986). The Class Room Sense of Community was developed to measure the sense of community among university students. The scale has 20 items, which measure sense of community in a education atmosphere. The researcher used 375 students enrolled in 28 diverse courses as a sample. Five point Likert scale has been used for items like (" I feel like I am encouraged to ask questions").5 Questions with Croncbach`s alpha or more were selected from the scale. The overall Croncbach`s alpha for the 20 item scale was 0.93 which give a sense of high reliability (Rovai, 2002).

\section{Academic Hardiness}

AcaHar scale is a 36 item instrument was used to measure the dimensions of AcaHar. Researchers distributed questionnaires to a sample of 1474 students. Results supported to Hardiness Theory (Control, Commitment and Challenge). The scale is based on five point Likert scale with items like " I do my best at school so as my marks to be higher than those of my classmates". 5 questions from each item of AcaHar(Control, Commitment and Challenge) with Croncbach's alpha 0.90 or more were selected. The scale overall reliability of 
Croncbach`s alpha is 0.89 . Further, authors suggested that factors in the scale are independent, therefore Control, Commitment and Challenge has been used separately to measure the overall AcaHar (Kamtsios \& Karagiannopoulou, 2012).

\section{Demographic Indicators}

Apart from AcaAch, classroom sense of community and AcaHar scales, students demographics were also collected through the same survey questionnaires. This includes gender, age, qualification and University registration ID. To collect cumulative grading point averages of students by giving different GPA ranges to two different university students, as Authors already mentioned there was no standard cumulative grading point average from Higher Education Commission of Pakistan, so different questionnaires were designed for two different university students with their respective grading point averages they used.

\section{Analysis}

The path model has been used to analyze the relation between AcaAch and Classroom sense of community. The model introduced by Lohmoller (1989) suggests that to increase or improve value of R2 this model can be used (Lohmöller, 1989). Further this model also recommended by (Henseler, 2012) and Hair (2014).

Table (6) path coefficient suggests the standardized coefficients. Path weights vary from 1 to 1 therefore the value near to the 1 is always consider as strongest path and near to 0 reflects weakest path. Table 05 suggests that AcaHar factors (Challenge, Commitment and control) has positive weak path or relationship with AcaAch where AcaHar (Com 0.232, Cont 0.1333) factors has positive moderate relationship with Classroom sense of community.

\section{Reliability analysis}

To develop questionnaire, instruments adapted from previous studies mentioned in literature. All items were selected on the basis of Cronbach alpha value (question carrying reliability value $>$ or equal 0.9 were selected). As demographics and culture influence reliability of the instrument; Thus, Factor analysis was used to check the reliability of constructs. 


\section{Internal consistency}

\section{Internal Consistency Reliability}

The internal consistency measures how reliable and consistent the items are designed to measure the latent construct (Bijttebier et al., 2000). Hair et al. (2011) suggested that a latent construct shall meet the criteria of composit reliability which should be equal or more than 0.7 . The coefficients of CR are shown in (Table 2) which suggests that all latent constructs of have loaded between 0.810 to 0.901 . Results indicates that all constructs meet requirement. These coefficient values advocate that construct used in this study have established adequate internal consistency reliability.

\section{Convergent Validity}

The convergent validity specifies that measures (items) of constructs used in the study are intended to measure the latent constructs and also correlates with other measures of the same construct (Hair et al., 2010). Convergent validity established through Average Variance Extracted (AVE) of the latent constructs. According to Chin (1998), AVE will be established if the loadings will be equal or greater than 0.5 of each latent construct. Table 2 suggests that AVE average variance extracted for the for latent constructs were ranging from 0.569 , and 0.6830 respectively. AVE values suggests that convergent validity is successfully established.

Table 3. shows that square root of the AV value propose that all the latent constructs have confirmed satisfactory level of discriminant validity; because all the values of AVE square root are greater than correlations. Results confirmed that all constructs of AcaHar meet the sufficient requirement of discriminant validity. Henseler, Ringle, \& Sinkovics, (2009) recommended these valuations. 


\section{i}

Table. 2 Convergent validity

\begin{tabular}{lllll}
\hline & $\begin{array}{l}\text { Cronbach's } \\
\text { Alpha }\end{array}$ & rho_A & $\begin{array}{l}\text { Composite } \\
\text { Reliability }\end{array}$ & (AVE) \\
\hline AcaAch & .560 & .662 & .810 & .683 \\
CSC & .863 & .868 & .901 & .646 \\
Chal & .855 & .858 & .896 & .634 \\
Com_ & .809 & .813 & .868 & .569 \\
Control & .864 & .874 & .901 & .646 \\
\hline
\end{tabular}

\section{Discriminant Validity}

The study also conducted the discriminant validly of the latent constructs used in the study. Duarte \& Raposo (2010). The discriminant validity means how latent variable is different from other latent constructses used in the study. (Duarte \& Raposo, 2010) suggests that discriminant validity measures that how one latent construct is deffrent from other construct. The square of AVE should be greater that the correlation among variables Fornell and Larcker, (1981). The square-root of AVE and correlations among constructs are provided in Table 3.

Table.3 Discriminant Validity

\begin{tabular}{llllll}
\hline & AcaAch & CSC & Chal & Com_ $_{-}$ & Control \\
\hline AcaAch & 0.827 & & & & \\
CSC & 0.012 & 0.804 & & & \\
Chal & 0.152 & 0.689 & 0.796 & & \\
Com_ & 0.133 & 0.640 & 0.689 & 0.755 & \\
Control & 0.125 & 0.625 & 0.690 & 0.726 & 0.804 \\
\hline
\end{tabular}


Table.4. Hypothesis

\begin{tabular}{|c|c|c|c|}
\hline Нypo 1 & $\begin{array}{l}\text { Classroom sense of community positively } \\
\text { (Control). }\end{array}$ & influence & AcaHar \\
\hline Нypo 2 & $\begin{array}{l}\text { Classroom sense of community positively } \\
\text { (Commitment). }\end{array}$ & influence & AcaHar \\
\hline Нypo 3 & $\begin{array}{l}\text { Classroom sense of community positively } \\
\text { (Challenge). }\end{array}$ & influence & AcaHar \\
\hline Нуро 4 & $\begin{array}{l}\text { Classroom sense of community positively } \\
\text { (control). }\end{array}$ & influence & AcaHar \\
\hline Нyро 4 & $\begin{array}{l}\text { Classroom sense of community positively } \\
\text { (Control) to increase (positively) AcaAch }\end{array}$ & influence & AcaHar \\
\hline Нyро 6 & $\begin{array}{l}\text { Classroom sense of community positively } \\
\text { (Commitment) to increase (positively) AcaAch }\end{array}$ & influence & AcaHar \\
\hline Нypo 7 & $\begin{array}{l}\text { Classroom sense of community positively } \\
\text { (Challenge) to increase (positively) AcaAch }\end{array}$ & influence & AcaHar \\
\hline Hypo 8 & $\begin{array}{l}\text { Gender will moderate relationship between } \\
\text { community and AcaAch }\end{array}$ & Classroom & sense of \\
\hline
\end{tabular}

\section{Measurement Model (Outer Model)}

Reflective and formative models always treated in a different way. As this research is based on reflective model therefore measurement of convergent and discernment validity is essential, which is established (See Table 3) (Gefen et al., 2000).

Bootstrapping were conducted (5000 sample) and all outer loadings are statistically significant at $\mathrm{p}$ value $(\mathrm{p}=0.1)$ level. Path analysis suggests that all the variables has positive relationships as hypothesised. Only two relationships are insignificant which are Com to AcaAch and Con to AcaAch (See Table 5). All the t-values are greater than the threshold level of 1.64. 


\section{i[CNEMF}

Table 5 Path Relationship

\begin{tabular}{lrrrrr}
\hline & $\begin{array}{l}\text { Original } \\
\text { Sample (O) }\end{array}$ & $\begin{array}{l}\text { Sample } \\
\text { Mean (M) }\end{array}$ & $\begin{array}{l}\text { Standard Deviation } \\
(\text { STDEV) }\end{array}$ & $\begin{array}{l}\text { T Statistics } \\
(\mid \mathrm{O} / \mathrm{STDEV})\end{array}$ & \multicolumn{1}{l}{$\begin{array}{l}\text { Palu } \\
\text { es }\end{array}$} \\
\hline $\begin{array}{l}\text { CSC -> } \\
\text { AcaAch }\end{array}$ & -0.214 & -0.226 & 0.120 & 1.781 & 0.037 \\
$\begin{array}{l}\text { CSC -> } \\
\text { Chal }\end{array}$ & 0.689 & 0.691 & 0.062 & 11.096 & 0.000 \\
$\begin{array}{l}\text { CSC -> } \\
\text { Com_- }\end{array}$ & 0.641 & 0.645 & 0.066 & 9.725 & 0.000 \\
$\begin{array}{l}\text { CSC -> } \\
\text { Control }\end{array}$ & 0.591 & 0.592 & 0.079 & 7.462 & 0.000 \\
$\begin{array}{l}\text { Chal -> } \\
\text { AcaAch }\end{array}$ & 0.223 & 0.230 & 0.115 & 1.941 & 0.026 \\
$\begin{array}{l}\text { Com_-> } \\
\text { AcaAch }\end{array}$ & 0.135 & 0.128 & 0.135 & 0.996 & 0.160 \\
$\begin{array}{l}\text { Control -> } \\
\text { AcaAch }\end{array}$ & -0.022 & -0.018 & 0.152 & 0.141 & 0.444 \\
\hline
\end{tabular}

There is no well-established Model of fit is defined in PLS. researchers can establish the fitness of model through path analysis (significance and R-Squres). R-Square measures the overall impact of exogenous variable on endogenous variable (See Table.6)

Table.6. R Square

\begin{tabular}{lrr}
\hline & R Square & R Square Adjusted \\
\hline AcaAch & 0.048 & 0.023 \\
Chal & 0.475 & 0.471 \\
Com_- & 0.411 & 0.407 \\
Control & 0.349 & 0.345 \\
\hline
\end{tabular}

Standards assessment criteria includes value or $\mathrm{Q}^{2}$ which is used to access the redundancy of the constructs under the method of blindfolding. The predictive relevance (Q2) value should be $>0$ (Chin, 2010). Also there is no collinearity problem among variables based on standard values of $>3.3$ or $>.5$ (Hair et al, 2017). 
Table 8 Variance Inflation Factor

\begin{tabular}{|c|c|c|c|c|}
\hline & $\mathrm{SSO}$ & SSE & $\mathrm{Q}^{2}(=1-\mathrm{SSE} / \mathrm{SSO})$ & VIF \\
\hline AcaAch & 316.000 & 317.144 & -0.004 & 1.178 \\
\hline CSC & 790.000 & 790.000 & & 2.016 \\
\hline Chal & 790.000 & 570.122 & 0.278 & 2.276 \\
\hline Com_ & 790.000 & 621.819 & 0.213 & 1.671 \\
\hline Control & 632.000 & 498.014 & 0.212 & 2.365 \\
\hline
\end{tabular}

Based on the Table. 9 beta coefficients are positive, $\mathrm{t}$ values are $>1.68$ and $\mathrm{p}$ values are significant at the level of 0.05. Therefore, accept Hypothesis 6 and 7 all hypothesis are accepted. These hypothesis suggests that commitment and control does not positively increase AcaAch.

Table.9 Hypothesis Acceptance

\begin{tabular}{|c|c|c|c|c|c|}
\hline & $\begin{array}{l}\text { Sample } \\
\text { Mean (M) }\end{array}$ & $\begin{array}{l}\text { Standard } \\
\text { Deviation } \\
\text { (STDEV) }\end{array}$ & $\begin{array}{l}\text { T Statistics } \\
(|\mathrm{O} / \mathrm{STDEV}|)\end{array}$ & P Values & Hypothesis \\
\hline $\begin{array}{l}\text { CSC -> } \\
\text { AcaAch }\end{array}$ & -0.226 & 0.120 & 1.781 & 0.037 & $\begin{array}{r}\mathrm{H} 1 \\
\text { Supported }\end{array}$ \\
\hline CSC -> Chal & 0.691 & 0.062 & 11.096 & 0.000 & $\begin{array}{r}\mathrm{H} 2 \\
\text { Supported }\end{array}$ \\
\hline $\begin{array}{l}\text { CSC -> } \\
\text { Com_ }\end{array}$ & 0.645 & 0.066 & 9.725 & 0.000 & $\begin{array}{r}\mathrm{H} 3 \\
\text { Supported }\end{array}$ \\
\hline $\begin{array}{l}\text { CSC -> } \\
\text { Control }\end{array}$ & 0.592 & 0.079 & 7.462 & 0.000 & $\begin{array}{r}\mathrm{H} 4 \\
\text { Supported }\end{array}$ \\
\hline $\begin{array}{l}\text { Chal -> } \\
\text { AcaAch }\end{array}$ & 0.230 & 0.115 & 1.941 & 0.026 & $\begin{array}{r}\mathrm{H} 5 \\
\text { Supported }\end{array}$ \\
\hline $\begin{array}{l}\text { Com_-> } \\
\text { AcaAch }\end{array}$ & 0.128 & 0.135 & 0.996 & 0.160 & $\begin{array}{r}\text { H6 Not } \\
\text { Supported }\end{array}$ \\
\hline $\begin{array}{l}\text { Control -> } \\
\text { AcaAch }\end{array}$ & -0.018 & 0.152 & 0.141 & 0.444 & $\begin{array}{r}\text { H7 Not } \\
\text { Supported }\end{array}$ \\
\hline
\end{tabular}




\section{i}

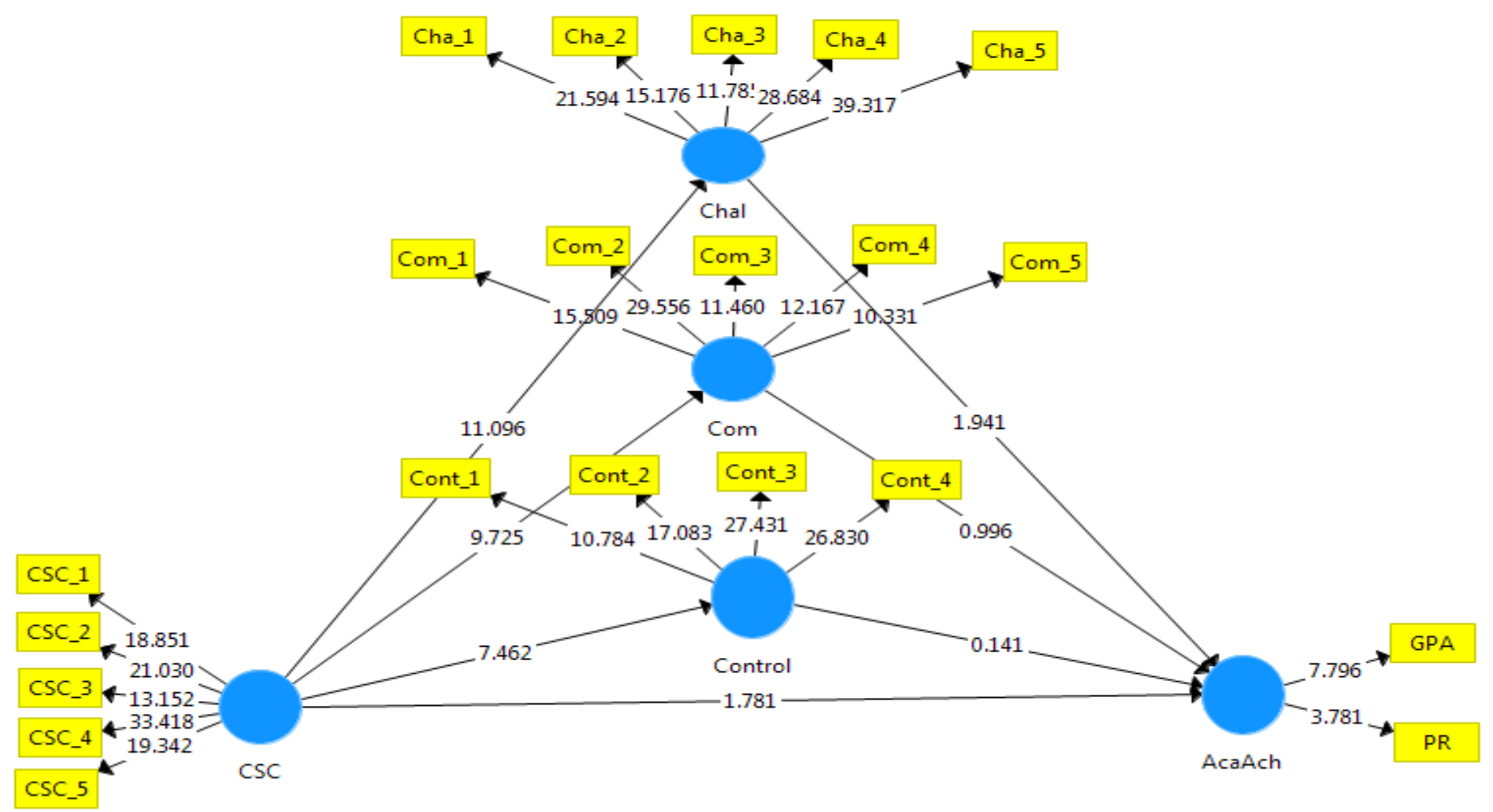

Mediation analysis of Academic Hardiness

The relationship between (CSC) and (AcaAch) is significant at $0.05 \mathrm{p}$ level as model summary in path analysis suggests that $\mathrm{R}$ square 0.048 means only 4 percent classroom sense of community affects AcaAch.

If X Effect Y which is CSC on AcaAch; there can be a causally located variable between them which is called mediator. Here mediator is AcaHar which is formed by three different constructs (Control, Commitment and Challenge). To know does this mediator mediates relationship between dependent and independent variable; the PLS bootstrap (5000) method were used. Which replicates the regression results and also specify the path relationships among variables that a significant relationship exist between CSC and AcaAch and has significant $(\mathrm{p}<0.05)$ relationship $(\mathrm{t}>1.68)$ with mediating variables Commitment $(\mathrm{t}=9.726, \mathrm{p}$ $=0.00)$, Control $(\mathrm{t}=7.46, \mathrm{p}=0.00)$ and Challenge $(\mathrm{t}=11.096, \mathrm{p}=0.037)$, where only Challenge 
$(\mathrm{t}=1.941, \mathrm{p}=0.026)$ mediates relationship between CSC and AcaAch but Control $(\mathrm{t}=0.141, \mathrm{p}$ $=0.444)$ and Commitment $(\mathrm{t}=0.996 \mathrm{p}=0.160)$ does not (See Table.9).

\section{Discussion}

The present study aimed to investigate the relationship of classroom sense of community with AcaHar along with mediating role of AcaHar and moderating role of gender. Findings of our research can contribute to fill the literature gap by (a) AcaHar as a mediator between classroom sense of community and AcaAch among Pakistani university students, (b) gender as a moderating variable between classroom sense of community and AcaAch among Pakistani university students.

AcaHar has been shown a positive correlation with AcaAch in university students and school students as well (Ahmadi, Zainalipour, \& Rahmani, 2013).

The Results from PLS procedure does not accept the hypothesis 6 and 7 but all other hypothesis are accepted by articulating classroom sense of community with AcaAch via AcaHar variables (control, commitment and challenge). Whereas, AcaAch can be influenced with lots of other factors, such as friends, teachers and family (Bentley, 1966). In Pakistan, Also, the results do not support the second hypothesis of the study that is gender as a moderator between classroom sense of community and AcaAch with Pakistani university students. Research concluded that there is no change in AcaAch by classroom sense of community between male and female.

Taking into account the importance of AcaAch for students, teachers, academicians, family and community, it is important for educationists, policy makers and educational psychologists to upgrade their knowledge regarding associations of AcaAch. The results of the present study provide in depth information for educationists, policy makers that can help them to have a better understanding of the relationship between classroom sense of community and AcaAch with mediating role of AcaHar and moderating role of gender. There is a dire need for more contribution in the existing literature regarding education in Pakistan, which can help educationists a lot to devise a effective and efficient educational policy in Pakistani dynamics. 


\section{i[CNEMF}

\section{Limitations}

There are quite a lot of limitations of the study that should kept in mind while interpreting the results. First, the present research is only based on two Higher Education Commission recognized universities, which may have impact the results. Second, the research was based on mixed university students, that may also have influenced the research results and may create hurdle in result generalization.

These limitations must be taken into account, the present result contributed in the existing literature and help in encouraging to do more research on the given topic. In specific, the study contributed in the literature by concluding no mediating role of AcaHar except challenge and moderating role of gender among Pakistani university students between classroom sense of community and AcaAch.

\section{Recommendations}

There is always a gap that needs to be filled. The present study contributed in the existing literature, but further research can be done by (a) adding more HEC recognized universities, (b) bi-forgetting undergrads, grads and postgraduates to get more practical picture, (c) selecting the age bracket to check the impact of classroom sense of community bracket wise.

\section{References}

Ahmadi, A., Zainalipour, H., \& Rahmani, M. (2013). Studying the Role of Academic Hardiness in Academic Achievement of Students of Islamic Azad University, Bandar Abbas Branch. Journal of Life Science and Biomedicine, 3(6), 418-423. Retrieved from http://jlsb.scienceline.com/attachments/article/26/J.\%20Life\%20Sci.\%20Biomed.\%203(6)\%20418423,\%202013.pdf

Alderman, H., Orazem, P. F., \& Paterno, E. M. (2001). School Quality, School Cost, and the Public/Private School Choices of Low-Income Households in Pakistan. The Journal of Human Resources, 36(2), 304-326. Retrieved from http://www.jstor.org/stable/3069661 


\section{i[C를}

Battle, J., \& Lewis, M. (2002, November). The Increasing Significance of Class: The Relative Effects of Race and Socio Economic Status on Academic Achievement. Journal of Poverty, 6(2), 21-35. doi:10.1300/J134v06n02_02

Beasley, M., Thompson, T., \& Davidson, J. (2003). Resilience in response to life stress: the effects of coping style and cognitive hardiness. Personality and Individual Differences, 34, 77-95.

Benishek, L. A., Feldman, J. M., Shipon, R. W., Mecham, S. D., \& Lopez, F. G. (2005, February 1). Development and Evaluation of the Revised Academic Hardiness Scale. Journal of Career Assessment, 13(1), 59-76. doi:https://doi.org/10.1177/1069072704270274

Bentley, J. C. (1966, February). Creativity and Academic Achievement. The Journal of Educational Research, 59(6), 269-272. doi:http://dx.doi.org/10.1080/00220671.1966.10883353

Blumberg, H., Kent, M., Haire, P. A., \& Davies, M. F. (1994). Small Group Research: Implications for Peace Psychology and Conflict Resolution. Springer Science and Business Media.

Bryk, A. S., \& Driscoll, M. E. (1998). The high school as community: contextual influences and consequences for students and teachers. Madison: National Center on Effective Secondary Schools, Wisconsin Center for Education Research, University of Wisconsin.

Chen, W.-W. (2015). The relations between perceived parenting styles and academic achievement in Hong Kong: The mediating role of students' goal orientations. Learning and Individual Differences, 37(1), 48-54. doi:dx.doi.org/10.1016/j.lindif.2014.11.021

Comrey, A. L., \& Lee, H. B. (1992). A first course in factor analysis (2nd ed.). Psychology Press.

Crosnoe, R., Johnson, M. K., \& Jr., G. H. (2004, December). School Size and the Interpersonal Side of Education: An Examination of Race/Ethnicity and Organizational Context. Social Science Quaterly, 85(5), 1259-1274. doi:10.1111/j.0038-4941.2004.00275.x

Csikszentmihalyi, M. (1975). Beyond Boredom and Anxiety. San Francisco: Jossey-Bass Publishers. Retrieved from http://psy2.ucsd.edu/ nchristenfeld/Happiness_Readings_files/Class\%207\%20$\% 20$ Csikszentmihalyi\%201975.pdf 


\section{iEnEMF}

Cutler, \& R.H. (1996). Communication and cyberspace: Social interaction in an electronic environment. Technologies, relations, and selves. In L. Strate, R. Jacobson, \& S.B. Gibson (Eds.), 317-333.

Eitle, T. M. (2005, August). Do Gender and Race Matter? Explaining the Relationship Between Sports Participation and Achievement. Sociological Spectrum, 25(2), 177-195. doi:10.1080/02732170590883997

Field, A. P. (2005). Discovering Statistics Using SPSS (2nd Edition). London: Sage.

Hair, J. J., Hult, G. M., Ringle, C. M., \& Sarstedt, M. (2014). A Primer on Partial Least Squares Structural Equation Modeling (PLS-SEM) (2nd ed.). Washington DC., USA: SAGE Publishers.

Hayes, A. F. (2013). Introduction to Mediation, Moderation and Conditional Process Analysis (A Regression-Bases Approach). New York: The Guilford Press.

Hox, J. J., \& Bechger, T. M. (1998). An Introduction to Structured Equation Modeling. Family Science Review, 11(4), 17. Retrieved from http://joophox.net/publist/semfamre.pdf

Kaiser, M. O. (1974). An index of factorial simplicity. . Psychometrika,.

Kamtsios, S., \& Karagiannopoulou, E. (2012, December). The development of a questionnaire on academic hardiness for late elementary school children. International Journal of Educational Research, 10. doi:http://dx.doi.org/10.1016/j.ijer.2012.12.001

Kendall, M. G., \& Gibbons, J. D. (1990). Rank Correlation Methods (5th ed.). London: . London: Edward Arnold.

Kobasa, S. C. (1979, January). Stressful Life Events, Personality and Health: An Inquiry Into Hardiness. Journal of Personality and Social Psychology, 37(1), 11.

Kobasa, S. C., Maddi, S. R., \& Kahn, S. (1982). Hardines and Health: A Prospective Study. Journal of Personality and Social Psychology, 42(1), 168-177.

McCoy, L. P. (2005, February). Effect of Demographic and Personal Variables on Achievement in Eighth-Grade Algebra. The Journal of Educational Research, 98(3), 131-135. Retrieved from http://www.jstor.org/stable/27548070

McMillan, D. W. (1996, October). Sense of Community. Journal of Community Psychology, 24(4), 315-325. doi:10.1002/(SICI)1520-6629(199610)24:4\%3C315::AIDJCOP2\%3E3.0.CO;2-T 
McMillan, D. W., \& Chavis, D. M. (1986). Sense of Community: A Definition and Theory. Journal of Community Psychology, 14(1), 6-23.

McMillan, D. W., \& Chavis, D. M. (1986, January). Sense of Community: A Definition and Theory. Journal of Community Psychology, 14(1), 18. Retrieved from http://onlinelibrary.wiley.com/doi/10.1002/1520-6629(198601)14:1\%3C6::AIDJCOP2290140103\%3E3.0.CO;2-I/abstract

Meyers, L. S., Gamst, G., \& Guraino, A. (2006). Applied Multivariate Research: Design and Interpretation. SAGE Publishers.

Moss, G. E. (1973). Illness, Immunity and Social Interaction: The Dynamics of Biosocial Resonation. John Wiley \& Sons Inc.

Nachtigall, C., Kroehne, U., Funke, F., \& Steyer, R. (2003). (Why) Should We Use SEM? : Pros and Cons of Structural Equation Modeling. Methods of Psychological Research Online, 8(2), 22. Retrieved from http://www.dgps.de/fachgruppen/methoden/mpronline/issue20/art1/mpr127_11.pdf

Preece, J. (2000). Online Communities: Designing Usability and Supporting Sociability. New York, USA: John Wiley \& Sons, Inc.

Rana, R. A., \& Mahmood, N. (2010, December). The Relationship Between Test Anxiety and Academic Achievement. Bulletin of Education and Research, 32(2), 63-74. Retrieved from https://ssrn.com/abstract=2362291

Rovai, A. P. (2001, December). Building Classroom Community at Distance: A Case Study. Educational Technology Research and Development, 49(4), 33-48. doi:10.1007/BF02504946

Rovai, A. P. (2002). Development of an instrument to measure classroom community. The Internet and Higher Education, 5, 15.

Rovai, A. P., Wighting, M. J., \& Lucking, R. (2004, November). The Classroom and School Community Inventory: Development, Refinement, and Validation of a Self-Report Measure for Educational Research. The Internet and Higher Education, 7(4), 263-280. doi:http://doi.org/10.1016/j.iheduc.2004.09.001

Selingman, M. E. (1992). Helplessness: On Depression, Development, and Death. San Francisco: APA.

Sergiovanni, \& J., T. (1994). Building community in schools (Vol. 21). San Francisco, CA, US: The Jossey-Bass education series. 
$2^{\text {nd }}$ International Conference on Research in BUSINESS, MANAGEMENT and FINANCE 27- 29 MARCH, $2020 \quad$ OXFORD, UNITED KINGDOM

\section{iF}

Thompson, B. (2004). Exploratory and confirmatory factor analysis: Understanding concepts and applications. Washington DC.: American Psychological Association. doi:http://psycnet.apa.org/doi/10.1037/10694-000

Vrasidas, C., \& Mclsaac, M. S. (2009, September). Factors influencing interaction in an online course. American Journal of Distance Education, 13(3), 22-36. doi:10.1080/08923649909527033 